\title{
Large-signal modeling of three-phase dual active bridge converters for electromagnetic transient analysis in DC grids
}

\author{
Maxime BERGER $^{1,2}$, Ilhan KOCAR $^{1}$ (i), Handy FORTIN-BLANCHETTE ${ }^{3}$, \\ Carl LAVERTU ${ }^{2}$
}

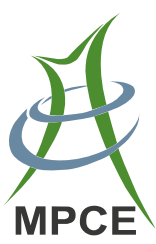

\begin{abstract}
The three-phase dual active bridge (3p-DAB) converter is widely considered in next-generation DC grid applications. As for traditional AC grids, the successful integration of power electronic converters in DC grids requires accurate time-domain system-level studies. As demonstrated in the existing literature, the development and efficient implementation of large-signal models of $3 p-$ DAB converters are not trivial. In this paper, a generalized average model is developed, which enables system-level simulation of DC grids with 3p-DAB converters in electromagnetic transient type (EMT-type) programs. The proposed model is rigorously compared with alternative modeling techniques: ideal-model, switching-function and state-space averaging. It is concluded that the generalized average model provides an optimal solution when accuracy of transient response, reduction in computation time, and wideband response factors are considered.
\end{abstract}

CrossCheck date: 28 February 2019

Received: 15 November 2018/Accepted: 28 February 2019/ Published online: 17 May 2019

(C) The Author(s) 2019

$\triangle$ Ilhan KOCAR

ilhan.kocar@polymtl.ca

Maxime BERGER

maxime.berger@polymtl.ca

Handy FORTIN-BLANCHETTE

handy.fortin-blanchette@etsmtl.ca

Carl LAVERTU

carl.lavertu@rail.bombardier.com

1 Polytechnique Montreal, Montreal, Canada

2 Bombardier Transportation, St-Bruno-de-Montarville, Canada

3 Ecole de Technologie Superieure, Montreal, Canada
Keywords Three-phase dual active bridge (3p-DAB), Generalized averaging, Large-signal analysis, Electromagnetic transient, DC-DC conversion

\section{Introduction}

There is a surge of interest in academic and industrial research on DC grids mainly due to their well-known advantages over $\mathrm{AC}$ grids in a number of applications $[1,2]$. DC distributions are being developed for applications such as transportation [3, 4], commercial and industrial buildings [5, 6], data centers [7], generating stations [8], and integration of distributed resources [9].

Power electronics interfaces play a key role in DC grids [10]. The three-phase dual active bridge (3p-DAB) DC-DC converter topology is widely considered to meet various requirements such as capability of bidirectional power flow, galvanic isolation, high efficiency and high power density [11-13]. The 3p-DAB also allows the use of different winding connections among which the $\mathrm{Y}-\Delta$ type connection has been shown to provide increased performance [14].

Small-signal frequency-domain modeling of converters is important in controller and filter design as well as the first stability assessments [15]. As for traditional AC grids, the integration of power electronics in DC grids also requires time-domain system-level studies such as voltage regulation performance with load variations, transient stability, and protection coordination [16-19]. Since the behavior of a converter depends on both its topology and controller, the closed-loop modeling of converters is necessary for system-level studies [20].

Each topology has its own particularities which should be considered in the development process of simulation 
models. Large-signal modeling of $3 p-D A B$ converters is not trivial because of its DC-AC-DC structure, three-phase transformer connections and higher number of switches compared to other isolated bidirectional DC-DC converter topologies [21]. The methodology presented in [22] is the first attempt to reduce the computation time for systemlevel studies with $3 \mathrm{p}$-DAB in electromagnetic transient type (EMT-type) programs. A discretized switching function (SWF) model in the $\alpha \beta$ frame is implemented. It reduces the number of electrical nodes while preserving the switching effect. However, it still requires time steps in the range of $1 / 1000^{\text {th }}$ of the switching period to maintain numerical stability. The reduction in the computation time compared to the ideal model approach is also not shown.

The ideal model approach is in fact well-known for the analysis of $3 p-D A B$ converters and other topologies because its implementation using ideal switches is straightforward in circuit simulation tools. Ideal model is a good reference for model validation [19, 23]. However, because the circuit topology is time-variant, and the switching effect is modeled, the computation time is demanding for system-level studies.

The SWF method [24] is proposed as an alternative methodology to ideal model in which the converter circuit is replaced by controlled voltage and current sources. Since the circuit topology is time-invariant, the SWF method reduces the computation time [17]. However, since it keeps the switching effect, small time steps are still required. Averaged models are well-known for neglecting the switching effect and allowing the use of larger simulation time steps which significantly reduce the computation time $[25,26]$.

In this paper, a generalized averaging model (GAM) of the $\mathrm{Y}-\Delta$ type $3 \mathrm{p}-\mathrm{DAB}$ converter is developed, implemented and compared with the ideal, SWF [24] and statespace averaging (SSA) [23, 25] methods [23, 25] in electromagnetic transient program (EMTP) [27] as shown in Fig. 1. In Fig. 1, simulation approaches indicated with a star * are compared in this paper. The ideal model is used

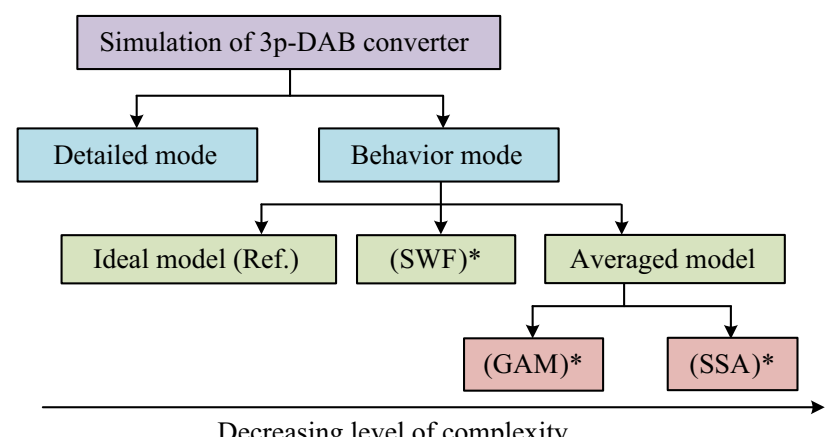

Fig. 1 Classification of simulation approaches for time-domain simulation of $3 p-D A B$ converter as a reference. The main contribution of this paper is to provide a solution to the challenges in developing and implementing a computational efficient and accurate model that enables time-domain system-level simulation of DC grids with 3p-DAB converters. By comparing the performance of the developed GAM with alternative modeling techniques, this paper also provides a complete comprehensive understanding of the advantages and limitations of the GAM approach for the 3p-DAB.

The paper is organized as follows. In Section 2, the operating principles of the $3 \mathrm{p}-\mathrm{DAB}$ converter are introduced. In Section 3, the development of the GAM model and its generalization to other transformer connections are presented. In Section 4, the performance of the GAM model is analyzed in terms of transient response, computation time and frequency response. A large-scale test system is also implemented to validate the performance of the GAM model for fault current and transient recovery voltage analysis.

\section{Operating principle of 3p-DAB converter}

The 3p-DAB converter topology is shown in Fig. 2a, where $v_{\mathrm{i}}$ is the input voltage; $v_{\mathrm{o}}$ is the output voltage; $i_{\mathrm{i}}$ is the input current; $i_{\mathrm{o}}$ is the output current; $\delta$ is the control phase-shift. Note that, throughout this paper, small letters are used for time-domain variables. Capital letters will be used for steady-state values. The phase-shift is denoted with $\delta=\delta(t)$ and its steady-state value with $D$.

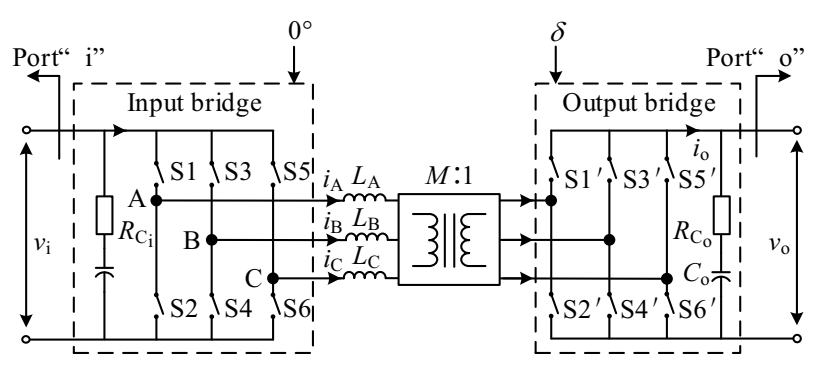

(a) 3p-DAB topology

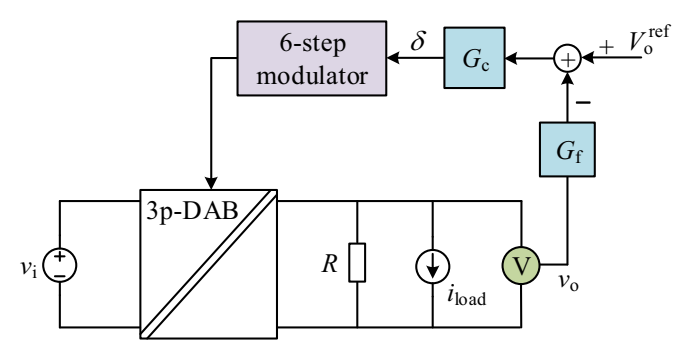

(b) Closed-loop control structure in forward operation

Fig. 2 3p-DAB converter 
The 3p-DAB is composed of two three-phase bridges connected through a three-phase medium-frequency transformer. It is most commonly operated using single phaseshift (SPS) control method with a fixed switching frequency $\omega_{\mathrm{s}}=2 \pi f_{\mathrm{s}}$, and a $180^{\circ}$ (or 6-step) modulation scheme $[14,28]$. Filter capacitors $C_{\mathrm{i}}$ and $C_{\mathrm{o}}$ are necessary to reduce the voltage ripple at $6 f_{\mathrm{s}}$ which is induced by both bridges. Their equivalent series resistances (ESRs), $R_{\mathrm{Ci}}$ and $R_{\mathrm{Co}}$, are also included because of their importance in stability analysis [29].

The phase-shift $\delta$ between the gating signals applied to the two bridges is the variable used to regulate the voltage of either one of the two ports. For example, in forward operation $(0 \leq \delta \leq \pi / 2)$, the active power is transferred from the input bridge to the output bridge such that $v_{\mathrm{o}}$ is regulated to reach its reference value $V_{\mathrm{o}}^{\text {ref }}$ shown in Fig. 2b. Reverse operation consists in reversing the sign of $\delta$ and regulating $v_{\mathrm{i}}$ to reach its reference value $V_{\mathrm{i}}^{\text {ref }}$. In Fig. $2 \mathrm{~b}, G_{\mathrm{c}}$ is the transfer function of the closed-loop controller and $G_{f}$ is the transfer function of the output voltage measurement filter. The current source $i_{\text {load }}$ is a load perturbation superimposed on the resistive load $R$ and is used to define the converter output impedance $Z_{\mathrm{o}}(s)$ in Section 4.5.

In steady state, the relationships between the input and output voltages for the $\mathrm{Y}-\Delta$ type $3 \mathrm{p}$-DAB converter are given as follows.

$V_{\mathrm{o}}= \begin{cases}\frac{m R D}{\omega_{\mathrm{s}} L_{\mathrm{s}}} V_{\mathrm{i}} & 0<D \leq \frac{\pi}{6} \\ \left(\frac{m R}{\omega_{\mathrm{s}} L_{\mathrm{s}}}\left[\frac{3}{2}\left(D-\frac{D^{2}}{\pi}\right)-\frac{\pi}{24}\right]\right) V_{\mathrm{i}} & \frac{\pi}{6} \leq D \leq \frac{\pi}{2}\end{cases}$

where $V_{\mathrm{i}}$ and $V_{\mathrm{o}}$ are the steady state input and output voltages; $R$ is the load resistance; $m$ is the transformer winding ratio $(m=M / \sqrt{3}) ; L_{\mathrm{s}}$ is the total transformer primary referred leakage inductance for which balanced operation is assumed $\left(L_{\mathrm{S}}=L_{\mathrm{A}}=L_{\mathrm{B}}=L_{\mathrm{C}}\right)$.

\section{Generalized averaging model}

The GAM method, also known as dynamic phasor [26], is a recognized methodology for the analysis of power electronics converters [30-34]. The idea is to decompose the converter state variables and its switching functions using a $k$ th coefficient Fourier series. For the $3 p-D A B$, it is proposed here to use only the index $k=0$ for the DC voltages, and the index $k= \pm 1$ for both the transformer $\mathrm{AC}$ currents and switching function components at the switching frequency $\omega_{\mathrm{s}}$. Higher harmonics are not considered because the three-phase structure leads to a next harmonic at $k=6$ which can generally be neglected in system-level studies. This will be shown in Section 4.1.

Seen from the DC grids, the GAM method leads to the equivalent index-0 model shown in Fig. 3. In Fig. 3, diodes $D_{\mathrm{i}}$ and $D_{\mathrm{o}}$ are used to model the clamping effect of the threephase bridge freewheeling diodes on negative voltage at the DC ports. Their importance is showed through an example in Section 4.3 . The index- 0 model is governed by a system of equations which is function of the index-1 model. The index1 model includes the AC dynamic of both the transformer currents and the switching functions shown in Fig. 4.

The large-signal model of the $3 p-D A B$ converter is given here using the following state-space notation:

$$
\begin{aligned}
& \frac{\mathrm{d}}{\mathrm{d} t}\langle\boldsymbol{x}\rangle=\boldsymbol{A}\langle\boldsymbol{x}\rangle+\boldsymbol{B}\langle\boldsymbol{u}\rangle \\
& \langle\boldsymbol{y}\rangle=\boldsymbol{C}\langle\boldsymbol{x}\rangle+\boldsymbol{D}\langle\boldsymbol{u}\rangle
\end{aligned}
$$

where $\langle\boldsymbol{x}\rangle,\langle\boldsymbol{u}\rangle,\langle\boldsymbol{y}\rangle$ are the vectors of averaged statevariables, inputs and outputs respectively:

$$
\begin{aligned}
& \langle\boldsymbol{x}\rangle=\left[\begin{array}{llllll}
\left\langle i_{\mathrm{A}}\right\rangle_{1}^{\mathrm{R}} & \left\langle i_{\mathrm{A}}\right\rangle_{1}^{\mathrm{I}} & \left\langle i_{\mathrm{B}}\right\rangle_{1}^{\mathrm{R}} & \left\langle i_{\mathrm{B}}\right\rangle_{1}^{\mathrm{I}} & \left\langle i_{\mathrm{C}}\right\rangle_{1}^{\mathrm{R}} & \left\langle i_{\mathrm{C}}\right\rangle_{1}^{\mathrm{I}}
\end{array}\right]^{\mathrm{T}} \\
& \langle\boldsymbol{u}\rangle=\left[\begin{array}{ll}
\left\langle v_{\mathrm{i}}\right\rangle_{0} & \left\langle v_{\mathrm{o}}\right\rangle_{0}
\end{array}\right]^{\mathrm{T}} \\
& \langle\boldsymbol{y}\rangle=\left[\begin{array}{ll}
\left\langle i_{\mathrm{i}}\right\rangle_{0} & \left\langle i_{\mathrm{o}}\right\rangle_{0}
\end{array}\right]^{\mathrm{T}}
\end{aligned}
$$

where the superscripts $\mathrm{R}$ and I denote the real and imaginary components of the averaged state-variables. The definition of the system matrices $\boldsymbol{A}, \boldsymbol{B}, \boldsymbol{C}$ and $\boldsymbol{D}$ which are time-dependent, requires to first write the index-0 input and output currents in terms of both the transformer primary currents, and the input and output bridge switching functions. The switching functions for the input bridge $s_{1}, s_{3}$, and $s_{5}$, and the output bridge $s_{1}^{\prime}, s_{3}^{\prime}, s_{5}^{\prime}$ are defined by the gating signals coming from the output of the modulator as shown in Fig. 4. For phase B, the switching functions $s_{3}$ and $s_{3}^{\prime}$ are $-120^{\circ}$ phase-shifted from phase A. For phase $\mathrm{C}$, the switching functions $s_{5}$ and $s_{5}^{\prime}$ are $+120^{\circ}$ phaseshifted from phase A.

The input current is given by:

$i_{\mathrm{i}}=s_{1} i_{\mathrm{A}}+s_{3} i_{\mathrm{B}}+s_{5} i_{\mathrm{C}}$

While (7) is valid for any transformer connection, the winding connection is included along with its ratio $m$ in the output current equation. For the $\mathrm{Y}-\Delta$ type $\left(-30^{\circ}\right)$ connection, it leads to:
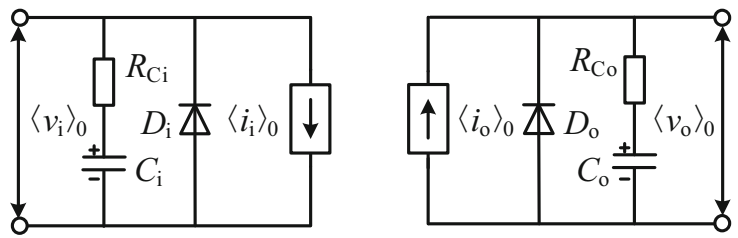

Fig. 3 Equivalent GAM of 3p-DAB seen from DC grids 


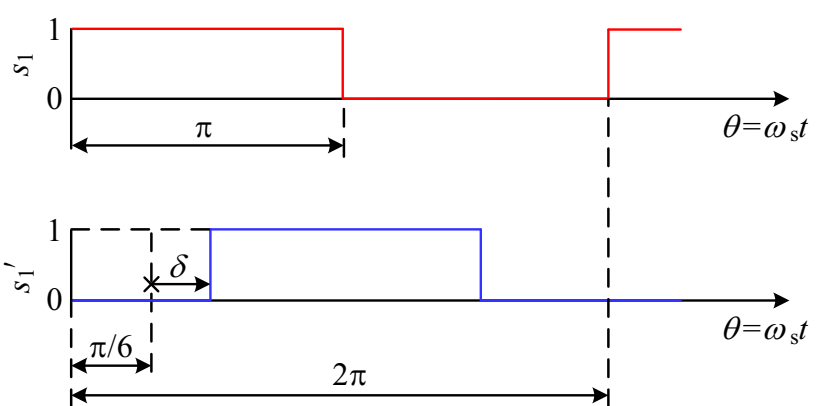

Fig. 4 Switching functions $s_{1}$ and $s_{1}^{\prime}$ of phase A for $\mathrm{Y}-\Delta$ type $\left(-30^{\circ}\right)$ transformer

$i_{\mathrm{o}}=m\left[\left(s_{1}^{\prime}-s_{3}^{\prime}\right) i_{\mathrm{A}}+\left(s_{3}^{\prime}-s_{5}^{\prime}\right) i_{\mathrm{B}}+\left(s_{5}^{\prime}-s_{1}^{\prime}\right) i_{\mathrm{C}}\right]$

where $s_{1}^{\prime}, s_{3}^{\prime}, s_{5}^{\prime}$ are dependent on the instantaneous value of the control phase-shift $\delta=\delta(t)$. To evaluate (7) and (8), the following primary transformer current equations should be solved:

$\frac{\mathrm{d} i_{\mathrm{A}}}{\mathrm{d} t}=\left(1 / L_{\mathrm{A}}\right)\left[\left(\left(2 s_{1}-s_{3}-s_{5}\right) / 3\right) v_{\mathrm{i}}-m\left(s_{1}^{\prime}-s_{3}^{\prime}\right) v_{\mathrm{o}}\right]$

$\frac{\mathrm{d} i_{\mathrm{B}}}{\mathrm{d} t}=\left(1 / L_{\mathrm{B}}\right)\left[\left(\left(2 s_{3}-s_{1}-s_{5}\right) / 3\right) v_{\mathrm{i}}-m\left(s_{3}^{\prime}-s_{5}^{\prime}\right) v_{\mathrm{o}}\right]$

$\frac{\mathrm{d} i_{\mathrm{C}}}{\mathrm{d} t}=\left(1 / L_{\mathrm{C}}\right)\left[\left(\left(2 s_{5}-s_{1}-s_{3}\right) / 3\right) v_{\mathrm{i}}-m\left(s_{5}^{\prime}-s_{1}^{\prime}\right) v_{\mathrm{o}}\right]$

Equations (7)-(11) are averaged using Fourier series properties [26, 35, 36]. The resulting system of equations defined by (2)-(6) and (12)-(18) is implemented in EMTP by the control blocks, and solved using [37]. The calculated values of the input current $\left\langle i_{\mathrm{i}}\right\rangle_{0}$ and the output current $\left\langle i_{\mathrm{o}}\right\rangle_{0}$ are used to control the current sources of Fig. 3. The system matrices are given by:

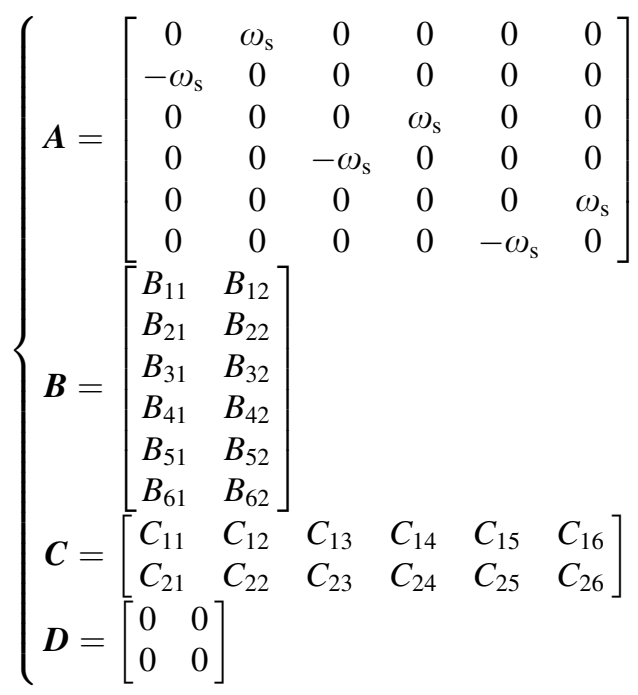

with

$$
\begin{aligned}
& \left\{\begin{array}{l}
B_{12}=\frac{m}{L_{\mathrm{A}}}\left(\left\langle s_{3}^{\prime}\right\rangle_{1}^{\mathrm{R}}-\left\langle s_{1}^{\prime}\right\rangle_{1}^{\mathrm{R}}\right) \\
B_{22}=\frac{m}{L_{\mathrm{A}}}\left(\left\langle s_{3}^{\prime}\right\rangle_{1}^{\mathrm{I}}-\left\langle s_{1}^{\prime}\right\rangle_{1}^{\mathrm{I}}\right) \\
B_{32}=\frac{m}{L_{\mathrm{B}}}\left(\left\langle s_{5}^{\prime}\right\rangle_{1}^{\mathrm{R}}-\left\langle s_{3}^{\prime}\right\rangle_{1}^{\mathrm{R}}\right) \\
B_{42}=\frac{m}{L_{\mathrm{B}}}\left(\left\langle s_{5}^{\prime}\right\rangle_{1}^{\mathrm{I}}-\left\langle s_{3}^{\prime}\right\rangle_{1}^{\mathrm{I}}\right) \\
B_{52}=\frac{m}{L_{\mathrm{C}}}\left(\left\langle s_{1}^{\prime}\right\rangle_{1}^{\mathrm{R}}-\left\langle s_{5}^{\prime}\right\rangle_{1}^{\mathrm{R}}\right) \\
B_{62}=\frac{m}{L_{\mathrm{C}}}\left(\left\langle s_{1}^{\prime}\right\rangle_{1}^{\mathrm{I}}-\left\langle s_{5}^{\prime}\right\rangle_{1}^{\mathrm{I}}\right)
\end{array}\right. \\
& \left\{\begin{aligned}
B_{11} & =\frac{1}{3 L_{\mathrm{A}}}\left[2\left\langle s_{1}\right\rangle_{1}^{\mathrm{R}}-\left\langle s_{3}\right\rangle_{1}^{\mathrm{R}}-\left\langle s_{5}\right\rangle_{1}^{\mathrm{R}}\right] \\
B_{21} & =\frac{1}{3 L_{\mathrm{A}}}\left[2\left\langle s_{1}\right\rangle_{1}^{\mathrm{I}}-\left\langle\mathrm{s}_{3}\right\rangle_{1}^{\mathrm{I}}-\left\langle s_{5}\right\rangle_{1}^{\mathrm{I}}\right] \\
B_{31} & =\frac{1}{3 L_{\mathrm{B}}}\left[2\left\langle s_{3}\right\rangle_{1}^{\mathrm{R}}-\left\langle s_{1}\right\rangle_{1}^{\mathrm{R}}-\left\langle s_{5}\right\rangle_{1}^{\mathrm{R}}\right] \\
B_{41} & =\frac{1}{3 L_{\mathrm{B}}}\left[2\left\langle s_{3}\right\rangle_{1}^{\mathrm{I}}-\left\langle s_{1}\right\rangle_{1}^{\mathrm{I}}-\left\langle s_{5}\right\rangle_{1}^{\mathrm{I}}\right] \\
B_{51} & =\frac{1}{3 L_{\mathrm{C}}}\left[2\left\langle s_{5}\right\rangle_{1}^{\mathrm{R}}-\left\langle s_{1}\right\rangle_{1}^{\mathrm{R}}-\left\langle s_{3}\right\rangle_{1}^{\mathrm{R}}\right] \\
B_{61} & =\frac{1}{3 L_{\mathrm{C}}}\left[2\left\langle s_{5}\right\rangle_{1}^{\mathrm{I}}-\left\langle s_{1}\right\rangle_{1}^{\mathrm{I}}-\left\langle s_{3}\right\rangle_{1}^{\mathrm{I}}\right]
\end{aligned}\right. \\
& \left\{\begin{array}{c}
C_{21}=2 m\left(\left\langle s_{1}^{\prime}\right\rangle_{1}^{\mathrm{R}}-\left\langle s_{3}^{\prime}\right\rangle_{1}^{\mathrm{R}}\right) \\
C_{22}=2 m\left(\left\langle s_{1}^{\prime}\right\rangle_{1}^{\mathrm{I}}-\left\langle s_{3}^{\prime}\right\rangle_{1}^{\mathrm{I}}\right) \\
C_{23}=2 m\left(\left\langle s_{3}^{\prime}\right\rangle_{1}^{\mathrm{R}}-\left\langle s_{5}^{\prime}\right\rangle_{1}^{\mathrm{R}}\right) \\
C_{24}=2 m\left(\left\langle s_{3}^{\prime}\right\rangle_{1}^{\mathrm{I}}-\left\langle s_{5}^{\prime}\right\rangle_{1}^{\mathrm{I}}\right) \\
C_{25}=2 m\left(\left\langle s_{5}^{\prime}\right\rangle_{1}^{\mathrm{R}}-\left\langle s_{1}^{\prime}\right\rangle_{1}^{\mathrm{R}}\right) \\
C_{26}=2 m\left(\left\langle s_{5}^{\prime}\right\rangle_{1}^{\mathrm{I}}-\left\langle s_{1}^{\prime}\right\rangle_{1}^{\mathrm{I}}\right)
\end{array}\right. \\
& \left\{\begin{array}{r}
C_{11}=2\left\langle s_{1}\right\rangle_{1}^{\mathrm{R}} \\
C_{12}=2\left\langle s_{1}\right\rangle_{1}^{\mathrm{I}} \\
C_{13}=2\left\langle s_{3}\right\rangle_{1}^{\mathrm{R}} \\
C_{14}=2\left\langle s_{3}\right\rangle_{1}^{\mathrm{I}} \\
C_{15}=2\left\langle s_{5}\right\rangle_{1}^{\mathrm{R}} \\
C_{16}=2\left\langle s_{5}\right\rangle_{1}^{\mathrm{I}}
\end{array}\right.
\end{aligned}
$$

For the input bridge, the averaged switching functions are constant because they do not depend on the control phase-shift. They are given by: 


$$
\left\{\begin{aligned}
\left\langle s_{1}\right\rangle_{1} & =\frac{1}{\pi} \mathrm{e}^{-\mathrm{j} \frac{\pi}{2}} \\
\left\langle s_{3}\right\rangle_{1} & =\frac{1}{\pi} \mathrm{e}^{\mathrm{j} \frac{\pi}{6}} \\
\left\langle s_{5}\right\rangle_{1} & =\frac{1}{\pi} \mathrm{e}^{\mathrm{j} \frac{5 \pi}{6}}
\end{aligned}\right.
$$

For the output bridge, they depend on the instantaneous value of the control phase-shift $\delta=\delta(t)$ and are referenced with respect to the input bridge:

$$
\left\{\begin{array}{l}
\left\langle s_{1}^{\prime}\right\rangle_{1}=\left\langle s_{1}\right\rangle_{1} \mathrm{e}^{-\mathrm{j}\left(\frac{\pi}{6}+\delta\right)} \\
\left\langle s_{5}^{\prime}\right\rangle_{1}=\left\langle s_{5}\right\rangle_{1} \mathrm{e}^{-\mathrm{j}\left(\frac{\pi}{6}+\delta\right)} \\
\left\langle s_{3}^{\prime}\right\rangle_{1}=\left\langle s_{3}\right\rangle_{1} \mathrm{e}^{-\mathrm{j}\left(\frac{\pi}{6}+\delta\right)}
\end{array}\right.
$$

\section{Performance comparison}

\subsection{Closed-loop time-domain transient response}

The transient response of the GAM model is first compared with equivalent closed-loop ideal, SWF and SSA models in EMTP. The converter parameters are given in Table 1.

Large-signal step function perturbations are applied and the resulting output voltage $v_{\mathrm{o}}$ is shown in Figs. 5, 6, 7 and 8. The results are analyzed in Section 4.6. In Fig. 5, the integration time step is $\Delta t=0.01 \mu$ s for the reference (Ref.) and SWF models, and $\Delta t=0.1 \mu$ s for the GAM and SSA models. In Fig. 6, it shows the converter output voltage when the input voltage is stepped from $800 \mathrm{~V}$ to $400 \mathrm{~V}$. It is observed that the SWF and GAM models consider the transient oscillations at the switching frequency $f_{\mathrm{s}}$. In Fig. 7 , converter output voltage when the load is stepped from high-load condition $(R=0.94 \Omega)$ to noload condition. It is concluded that all the models consider the transient oscillations at the cross-over frequency $f_{\varphi \mathrm{m}}$. In Fig. 8, it is shown that only the SWF model includes the ripple at $6 f_{\mathrm{s}}$. The component at $6 f_{\mathrm{s}}$ is negligible in large-

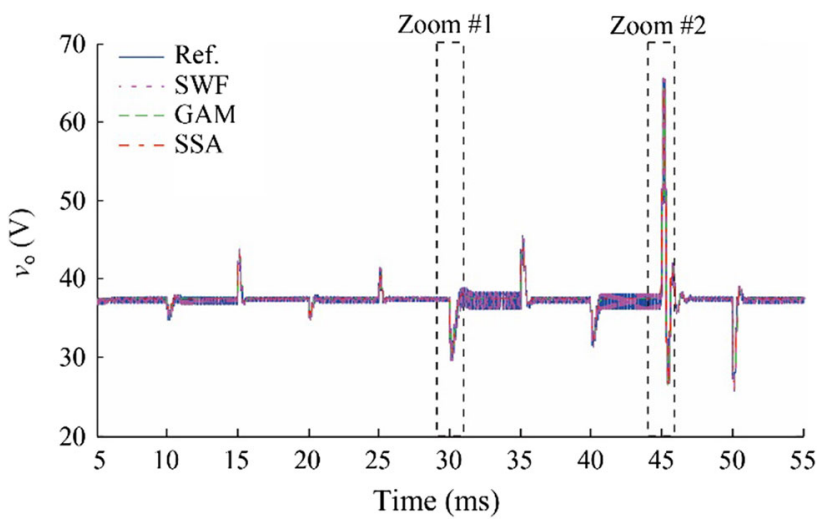

Fig. 5 Simulation results for complete simulation run

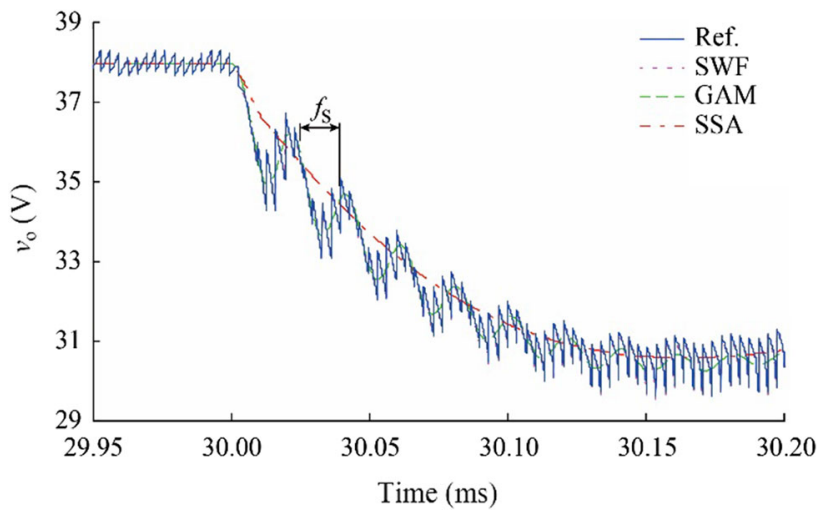

Fig. 6 Zoom \#1 on simulation results

signal studies because the ripple at $6 f_{\mathrm{s}}$ is generally significantly attenuated by $C_{\mathrm{o}}$.

\subsection{Simulation timing analysis}

When performing system-level studies, the simulation time step $\Delta t$ is generally selected based on the frequency spectra of the targeted power system studies. In the case of many power electronic converters, even for low-frequency phenomena, if the switching effect is modeled, it is

Table 13 -DAB converter parameters

\begin{tabular}{lll}
\hline Parameters & Symbol & Value \\
\hline Output voltage set point & $V_{\mathrm{o}}^{\text {ref }}$ & $37.5 \mathrm{~V}$ \\
Input capacitor & $C_{\mathrm{i}}, R_{\mathrm{Ci}}$ & $660 \mathrm{nF}, 40 \mathrm{~m} \Omega$ \\
Output capacitor & $C_{\mathrm{o}}, R_{\mathrm{Co}}$ & $150 \mu \mathrm{F}, 60 \mathrm{~m} \Omega$ \\
Transformer leakage inductance & $L_{\mathrm{s}}$ & $420 \mu \mathrm{H}$ \\
Transformer ratio & $M$ & 16 \\
$G_{\mathrm{c}}$ cross-over frequency (PI-type) & $f_{\varphi \mathrm{m}}$ & $1.5 \mathrm{kHz}$ \\
$G_{\mathrm{c}}$ phase-margin (PI-type) & $\varphi_{\mathrm{m}}$ & $45^{\circ}$ \\
Low-pass filter $G_{\mathrm{f}}(2 \mathrm{nd}$ order Butterworth) & $f_{\mathrm{o}}$ & $5 \mathrm{kHz}$ \\
\hline
\end{tabular}




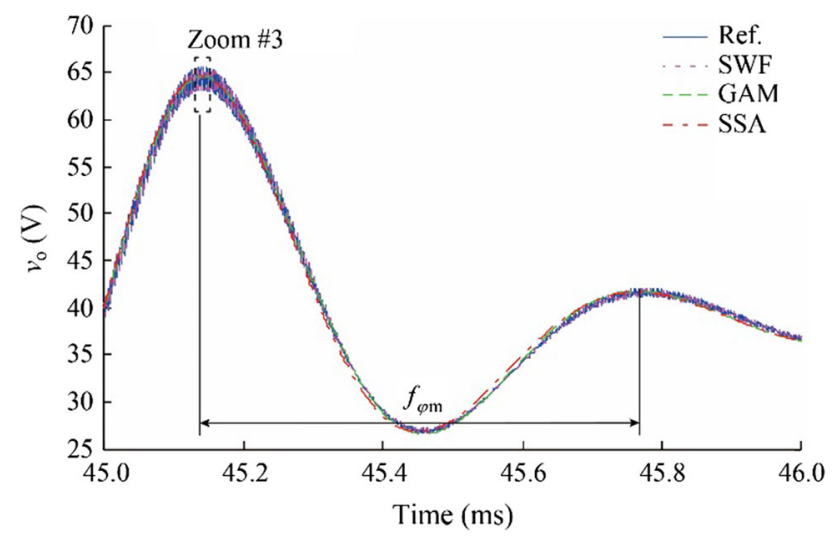

Fig. 7 Zoom \#2 on simulation results

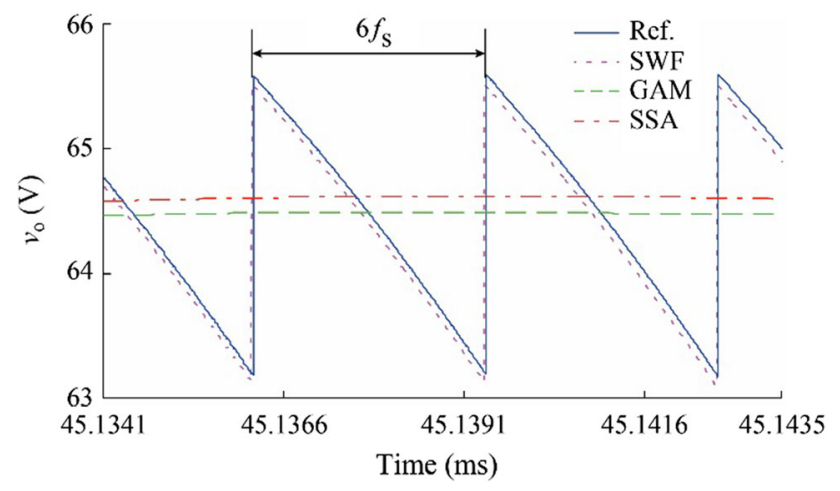

Fig. 8 Zoom \#3 on simulation results

necessary to reduce the time step $\Delta t$ to typically $1 / 100^{\text {th }}$ of the switching period $1 / f_{\mathrm{s}}$ (rule of thumb). In the case of the $3 \mathrm{p}-\mathrm{DAB}$, since the ripple is at $6 f_{\mathrm{s}}$, it requires having a time step smaller than around $1 / 600^{\text {th }}$ of the switching period. This problem has been highlighted in [22] for the specific case of the 3 p-DAB converter.

Since the computation time $t_{\mathrm{cpu}}$ highly depends on the integration time step $\Delta t$, multiple simulation runs as in Fig. 5 have been performed to thoroughly compare the models. The results are shown in Fig. 9 and are further analyzed in Section 4.6. An Intel ${ }^{\circledR}$ Core $^{\mathrm{TM}}$ processor i74700HQ (2.4 GHz) with $12 \mathrm{~GB}$ of RAM, and EMTP-RV software version 3.4 is used. The simulation time $t_{\text {sim }}=60$ ms.

\subsection{Transient short circuit with multiple 3p-DAB converters}

A bolted fault of $20 \mathrm{~ms}$ duration is applied at the output of ten $3 p-D A B$ converters connected in parallel through RL devices which model typical converter input filters and output cables. An output VI-characteristic with a $2 \%$ droop centered on $V_{\mathrm{o}}^{\text {nom }}=37.5 \mathrm{~V}$, and a $10 \%$ maximum current

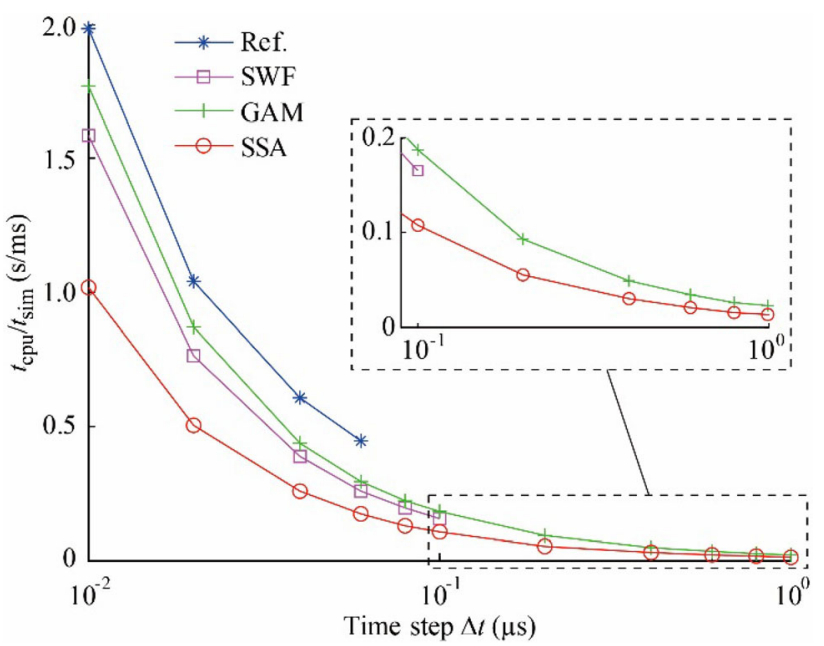

Fig. 9 Computation time for different integration time step $\Delta t$ for simulation scenario of Fig. 5

limit $I_{\mathrm{o}}^{\max }=30 \mathrm{~A}$ is implemented to model a common converter fault protection scheme shown in Fig. 10 [4].

The transient short circuit current for each model is shown in Fig. 11. The maximum integration time step obtained in Fig. 9 is used for each model, i.e., $\Delta t=0.06 \mu \mathrm{s}$ for the Ref. model, $\Delta t=0.1 \mu$ s for the SWF model, and $\Delta t=1 \mu \mathrm{s}$ for the GAM and SSA models. The converter is operated at $V_{\mathrm{s}}=600 \mathrm{~V}$ and $f_{\mathrm{s}}=50 \mathrm{kHz}$.

A breakdown analysis of the CPU effort is also shown in Fig. 12. The results are also analyzed together in Section 4.6.

Moreover, diodes $D_{\mathrm{i}}$ and $D_{\mathrm{o}}$ are used to model the clamping effect of the 3p-DAB freewheeling diodes on negative voltage at the DC ports. These diodes are always present in practical applications. Their importance on system-level simulation accuracy is shown in Fig. 13 by comparing the ideal model results with the SWF, GAM and SSA model results without $D_{\mathrm{i}}$ and $D_{\mathrm{o}}$. These diodes are often neglected but their impact may not be negligible as shown experimentally in [38].

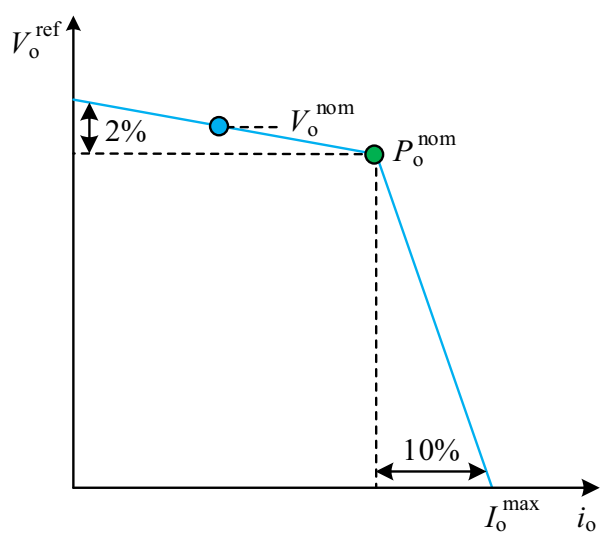

Fig. 10 Internal VI-characteristic of each 3p-DAB converter 


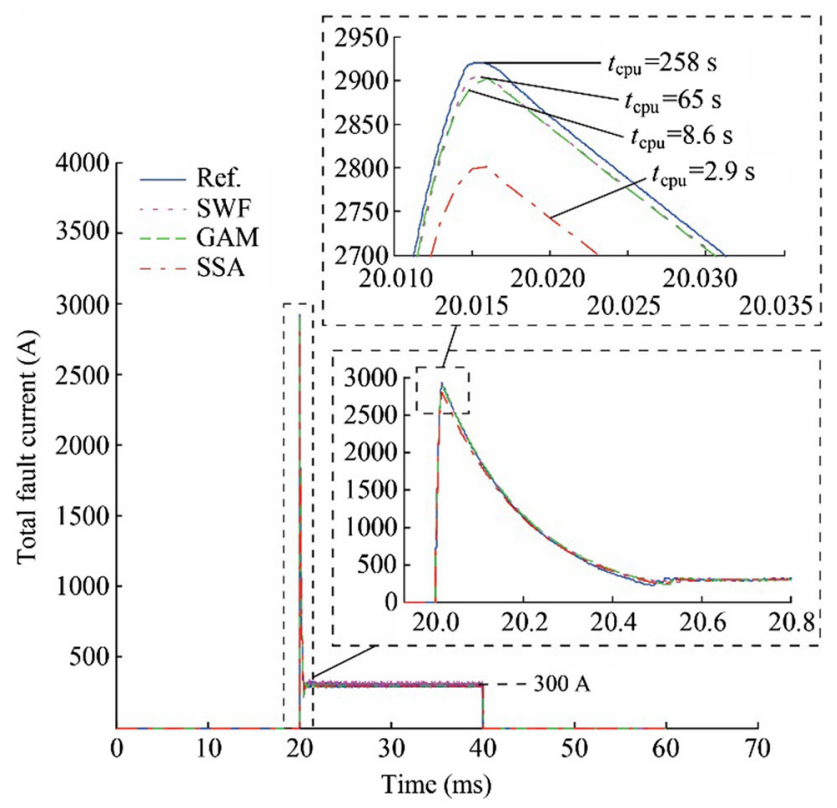

Fig. 11 Simulation results for a bolted fault at the output of ten $3 p$ $\mathrm{DAB}$ in parallel

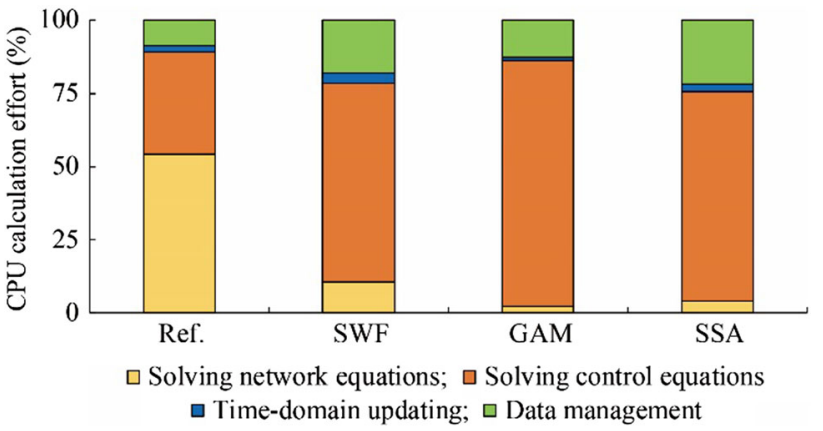

Fig. $12 \mathrm{CPU}$ calculation effort of total computation time $t_{\mathrm{cpu}}$

\subsection{Validation of GAM for power system transient analysis in a large-scale test system}

The effectiveness and accuracy of the GAM model to study large-scale systems are validated through a short circuit test case in which the transient fault current as well as the transient recovery voltages at fault clearing are analyzed.

A single line diagram of the test system is shown in Fig. 14. It is composed of a primary voltage ring bus at $750 \mathrm{~V}$, two intermediate voltage bus at $380 \mathrm{~V}$, and a low voltage ring bus at $110 \mathrm{~V}$. The system is divided into ten identical regions with a total of 203 p-DAB converters. All the converters are designed with an LC input filter. The parameters of the $3 \mathrm{p}-\mathrm{DAB}$ converters used in this test case are provided in Table 2. Cables are modeled with equivalent RL circuits (not shown in Fig. 14). Detailed models of battery $[4,39]$, circuit breaker detection and arcing [4, 40],

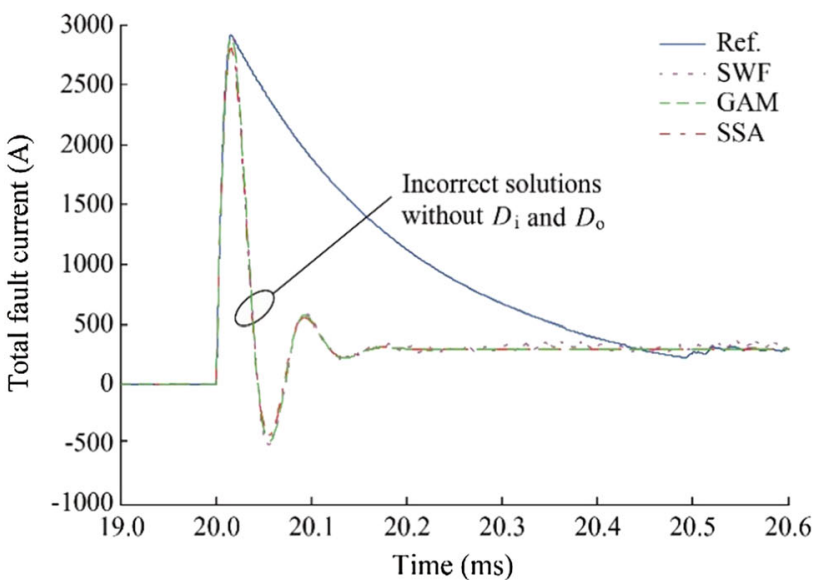

(a) Total fault current

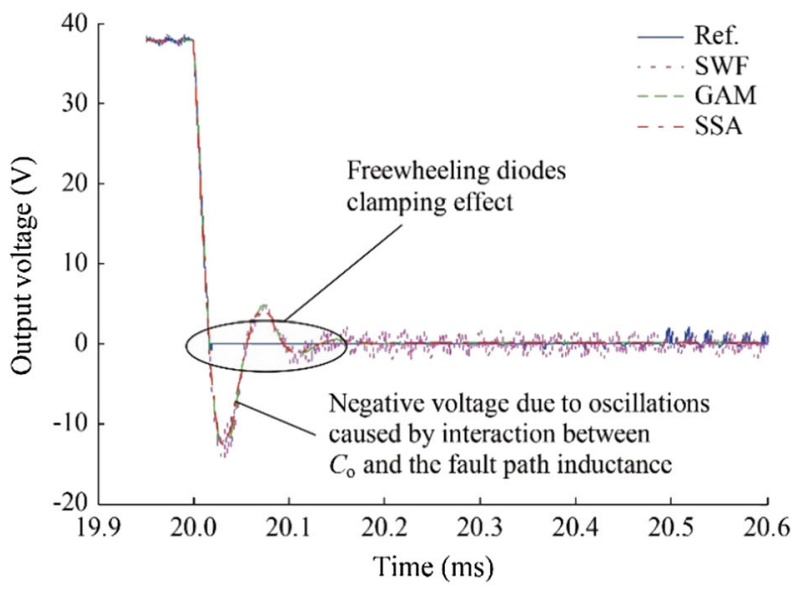

(b) Output voltage at one of the converter terminals

Fig. 13 Simulation results for a bolted fault at the output of ten 3pDAB connected in parallel without $D_{\mathrm{i}}$ and $D_{\mathrm{o}}$ for the SWF, GAM and SSA models

fuse detection and arcing [38], as well as metal oxide varistor (MOV) [38] are used. More details on the mathematical formulation and the implementation of each model can be found in the references provided above.

At $t=20 \mathrm{~ms}$, a $1 \mathrm{~m} \Omega$ fault is applied in region 6 of the $110 \mathrm{~V}$ bus shown in Fig. 14. The short circuit current and the sequence of events are shown in Fig. 15 while the transient recovery voltage (V5 in Fig. 14) is given in Fig. 16. These results confirm that the developed GAM can be used for accurate grid-level analyses such as fault current evaluation and transient recovery voltage assessment.

The total simulation time $t_{\text {sim }}$ is $50 \mathrm{~ms}$. For the reference model, the integration time step $\Delta t$ is $0.05 \mu \mathrm{s}$, and the total computation time $t_{\mathrm{cpu}}$ is $4565 \mathrm{~s}$. This is the largest time step that can be used to maintain numerical stability. For the GAM, the integration time step $\Delta t$ is increased to $1 \mu \mathrm{s}$ such as the total computation time is significantly reduced to $t_{\mathrm{cpu}}=45 \mathrm{~s}$. 


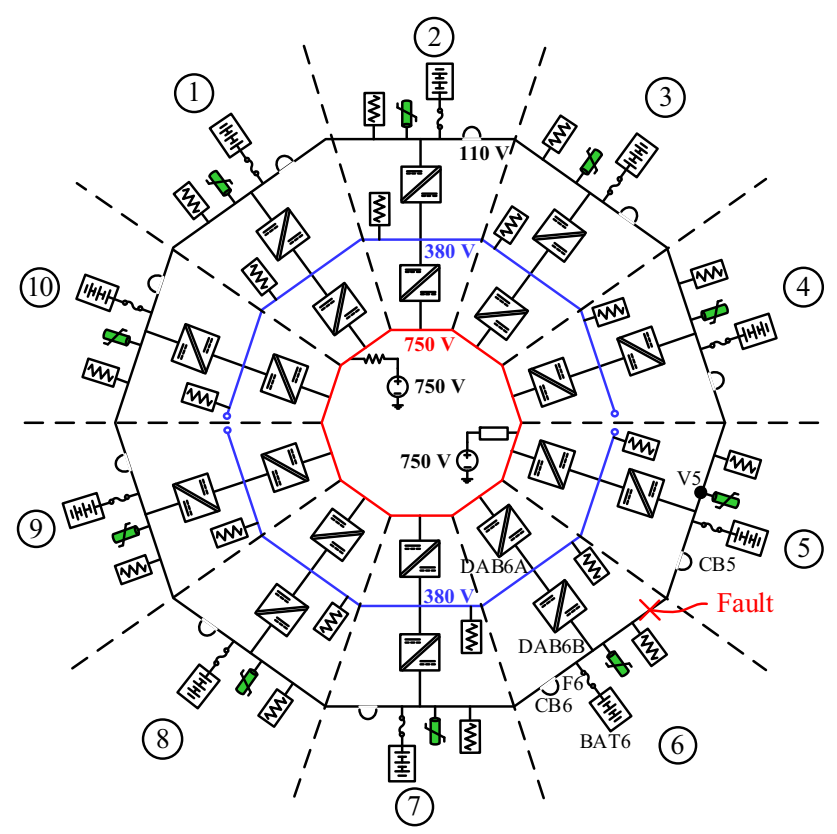

Fig. 14 Large-scale test system for validation of GAM

Table 2 Summary of 3p-DAB parameters for large-scale test system

\begin{tabular}{lll}
\hline Parameter & DABXA* & DABXB* \\
\hline Nominal input voltage $V_{\mathrm{i}}^{\text {nom }}$ & $750 \mathrm{~V}$ & $380 \mathrm{~V}$ \\
Nominal output voltage set-point $V_{\mathrm{o}}^{\text {nom }}$ & $380 \mathrm{~V}$ & $110 \mathrm{~V}$ \\
Nominal output power $P_{\mathrm{o}}^{\text {nom }}$ & $100 \mathrm{~kW}$ & $10 \mathrm{~kW}$ \\
Maximum output current $I_{\mathrm{o}}^{\max }$ & $290 \mathrm{~A}$ & $100 \mathrm{~A}$ \\
Input capacitor $C_{\mathrm{i}}$ & $1100 \mu \mathrm{F}$ & $150 \mu \mathrm{F}$ \\
Input filter inductor $L_{\mathrm{i}}$ & $100 \mu \mathrm{H}$ & $50 \mu \mathrm{H}$ \\
Output capacitor $C_{\mathrm{o}}$ & $2200 \mu \mathrm{F}$ & $150 \mu \mathrm{F}$ \\
Transformer leakage inductance $L_{\mathrm{s}}$ & $10 \mu \mathrm{H}$ & $12 \mu \mathrm{H}$ \\
Transformer ratio $M$ & 1.732 & 3.45 \\
Switching frequency $f_{\mathrm{s}}$ & $20 \mathrm{kHz}$ & $50 \mathrm{kHz}$ \\
$G_{\mathrm{c}}$ cross-over frequency (PI-type) $f_{\varphi \mathrm{m}}$ & $1.5 \mathrm{kHz}$ & $2.5 \mathrm{kHz}$ \\
$G_{\mathrm{c}}$ phase-margin $\left(\mathrm{PI}-\right.$ type) $\varphi_{\mathrm{m}}$ & $45^{\circ}$ & \\
Low-pass filter $G_{\mathrm{f}}\left(2 \mathrm{nd}\right.$ order Butterworth) $f_{\mathrm{o}}$ & $5 \mathrm{kHz}$ & \\
\hline
\end{tabular}

Note: $* X=1,2, \ldots, 10$

\subsection{Closed-loop frequency-domain response}

As seen in Fig. 7, the main frequency component of the oscillations in the closed-loop response is close to the cross-over frequency of the designed PI controller, i.e. $f_{\varphi \mathrm{m}}=1.5 \mathrm{kHz}$.

However, as previously mentioned, for system-level studies, the frequency content is a function of the aimed power system analysis. This means that, instead of being

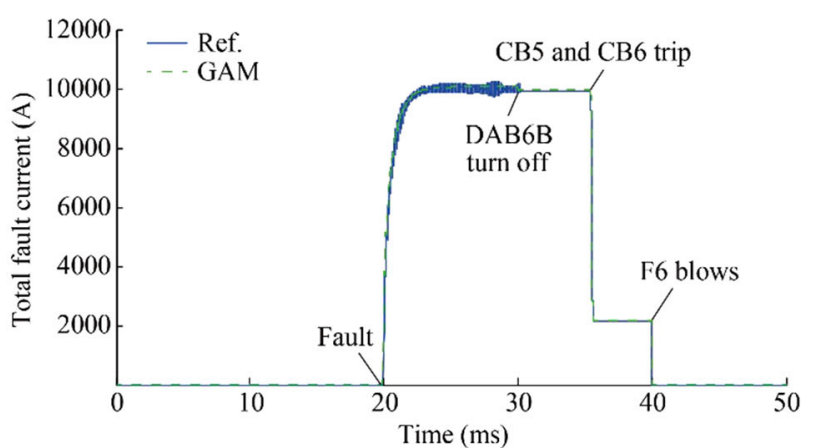

(a) Fault current for the complete simulation run

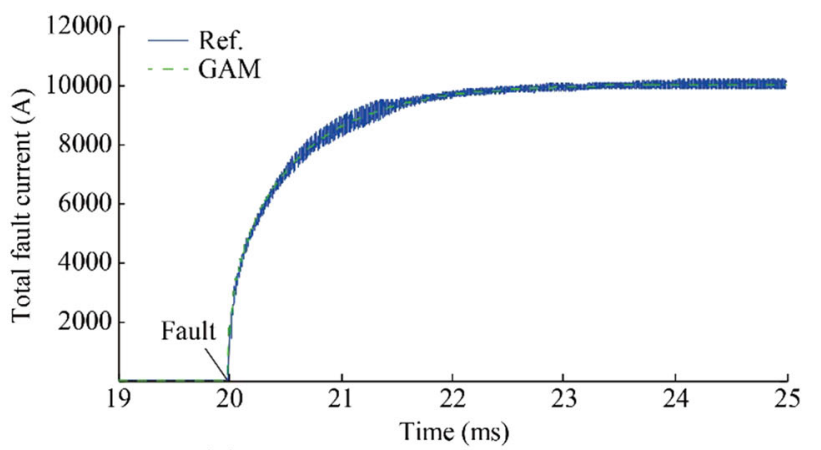

(b) Transient fault current at fault application

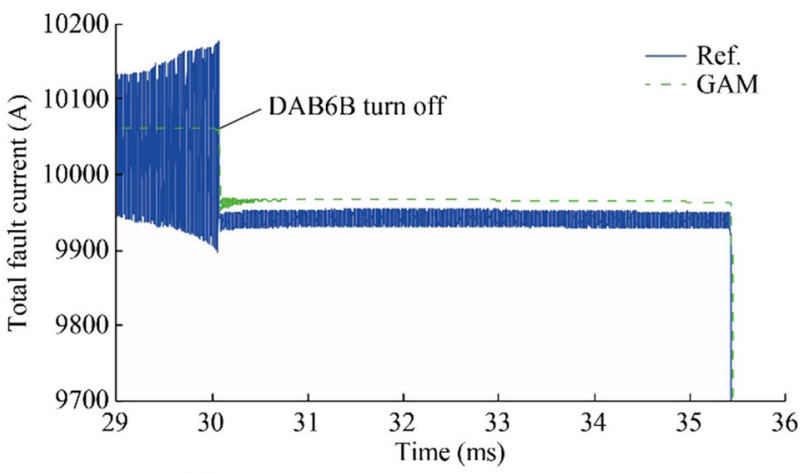

(c) Transient fault current after DAB6B turn off

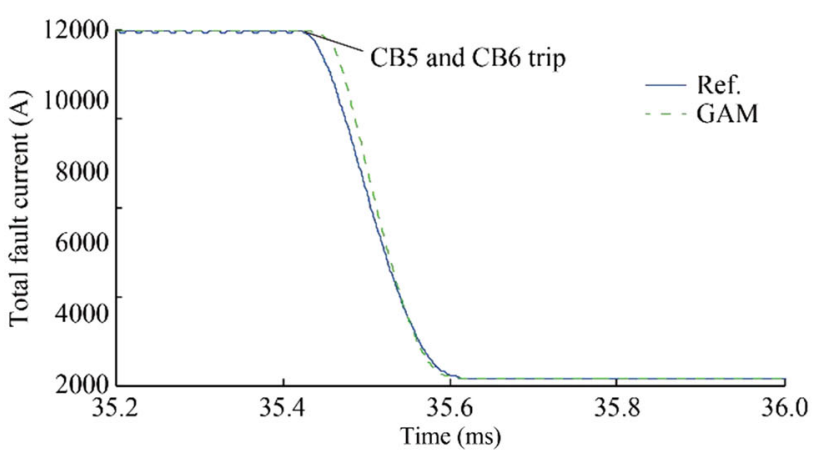

(d) Transient fault current during CB5 and CB6 arcing

Fig. 15 Analysis of transient fault current at fault application and during fault clearing

step functions, the large-signal perturbations may contain a large spectrum of frequencies. 


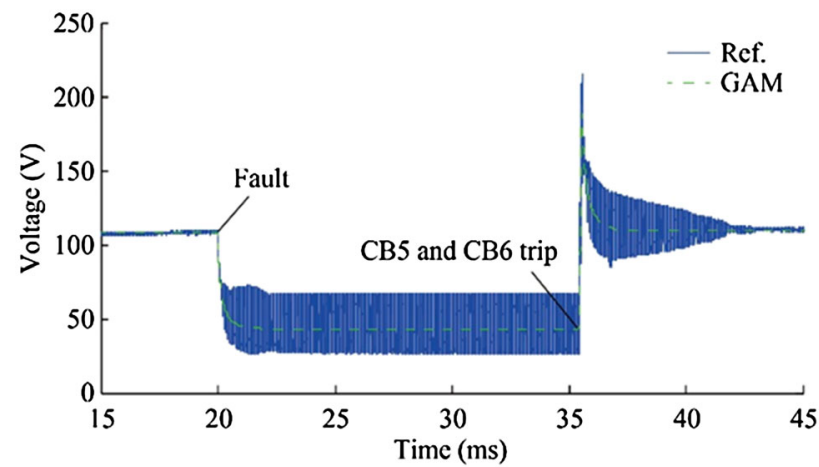

(a) Voltage at fault application and fault clearing

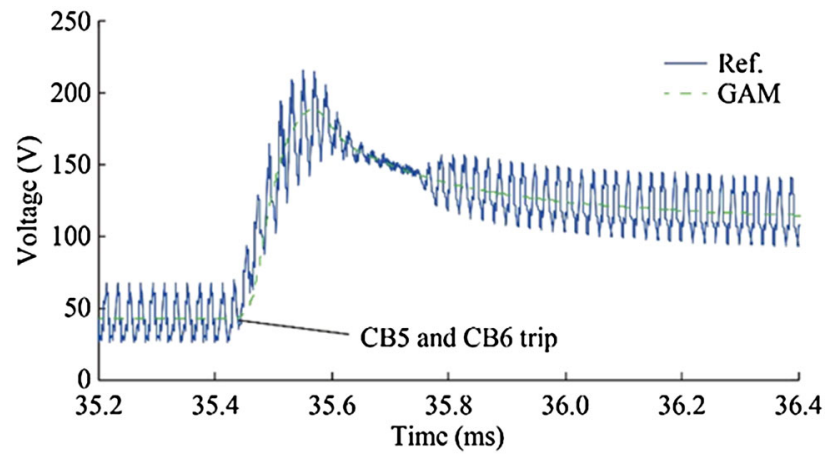

(b) Transient recovery voltage during arcing of $\mathrm{CB} 5$ and $\mathrm{CB} 6$

Fig. 16 Analysis of voltage during fault application and fault clearing

Therefore, the precision of the models at different frequencies is assessed here. For system-level analysis, the input-to-output voltage relationship $G_{\mathrm{vg}}^{\mathrm{c}}(s)=\left.\left(v_{\mathrm{o}}(s) / v_{\mathrm{i}}(s)\right)\right|_{i_{\text {load }}(s)=0}$, the load rejection behavior (also known as back-current gain) $G_{\text {load }}^{\mathrm{c}}(s)=\left.\left(i_{\mathrm{i}}(s) / i_{\text {load }}(s)\right)\right|_{v_{\mathrm{i}}(s)=0}$, the input impedance $Z_{\text {in }}^{\mathrm{c}}(s)=\left.\left(v_{\mathrm{i}}(s) / i_{\mathrm{i}}(s)\right)\right|_{i_{\text {load }}(s)=0}$ and the output impedance $Z_{\mathrm{o}}^{\mathrm{c}}(s)=-\left.\left(v_{\mathrm{o}}(s) / i_{\text {load }}(s)\right)\right|_{v_{\mathrm{i}}(s)=0}$ are the main closed-loop transfer functions of interest.

The transfer functions $G_{\mathrm{vg}}^{\mathrm{c}}$ and $G_{\mathrm{load}}^{\mathrm{c}}$ are particularly interesting because they show how perturbations at the input of the converter propagate at the output and viceversa. The input and output impedances, defined by $Z_{\text {in }}^{\mathrm{c}}$ and $Z_{\mathrm{o}}^{\mathrm{c}}$ respectively, are also relevant because, by definition, they show the local reaction of the converter to perturbations at either one of the ports.

The models are validated by applying sine wave perturbations at different frequencies in the simulation models with the parameters shown in Table 1. The perturbations frequency is varied from $100 \mathrm{~Hz}$ up to the switching frequency $f_{\mathrm{s}}=50 \mathrm{kHz}$. The magnitude of the output signals is extracted by FFT analysis. The results are shown in Fig. 17 and further analyzed in Section 4.6. In Fig. 17, the converter is operated at the following operating point: $V_{\mathrm{i}}$ $=600 \mathrm{~V}, V_{\mathrm{o}}=37.5 \mathrm{~V}, P_{\mathrm{o}}=1 \mathrm{~kW}$.

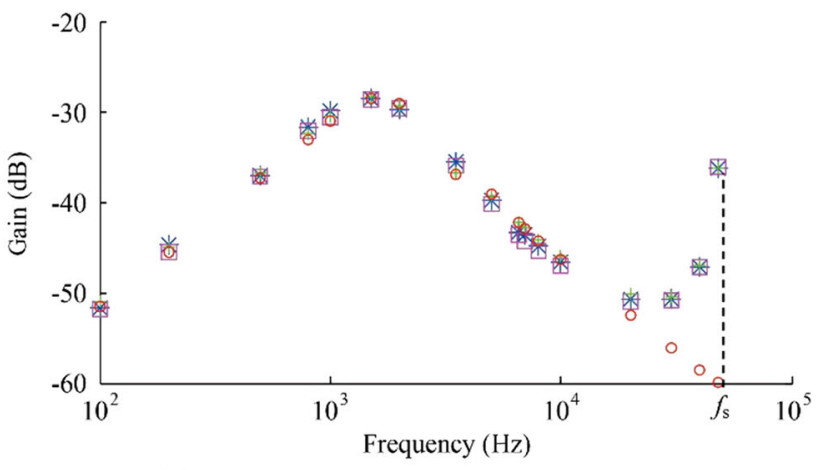

(a) Closed-loop input-1o-output voltage gain $\left|G_{\mathrm{vg}}^{\mathrm{c}}(s)\right|$

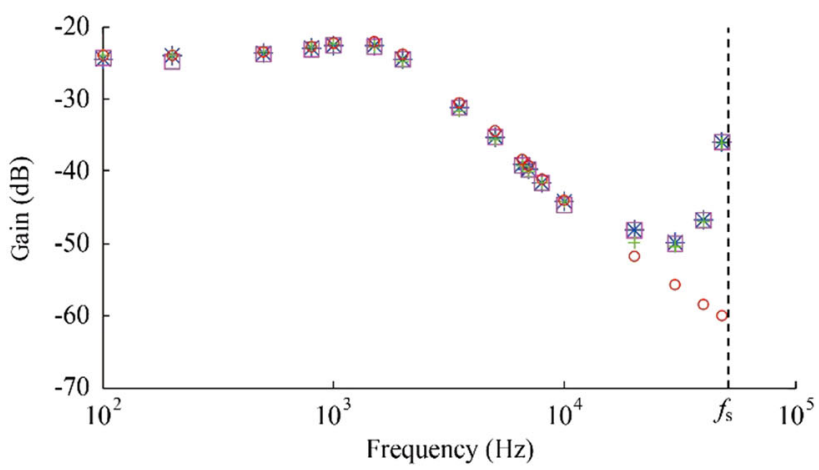

(b) Closed-loop load rejection gain $\left|G_{\text {load }}^{\text {c }}(s)\right|$

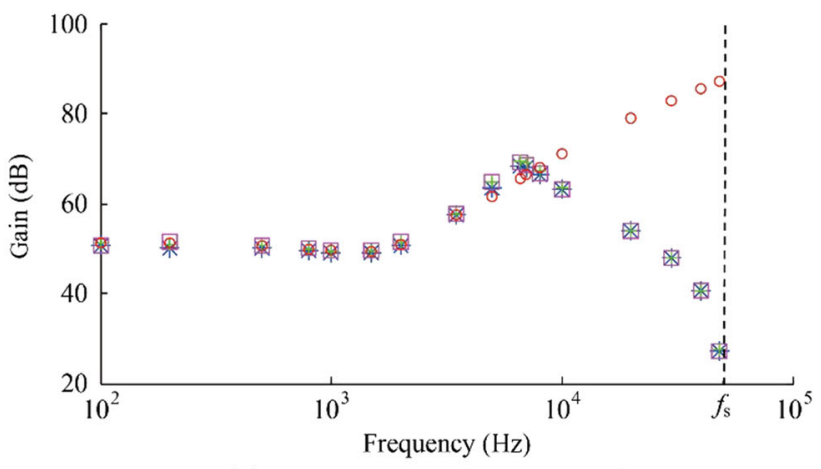

(c) Closed-loop input impedance $\left|Z_{\text {in }}^{\text {c }}(s)\right|$

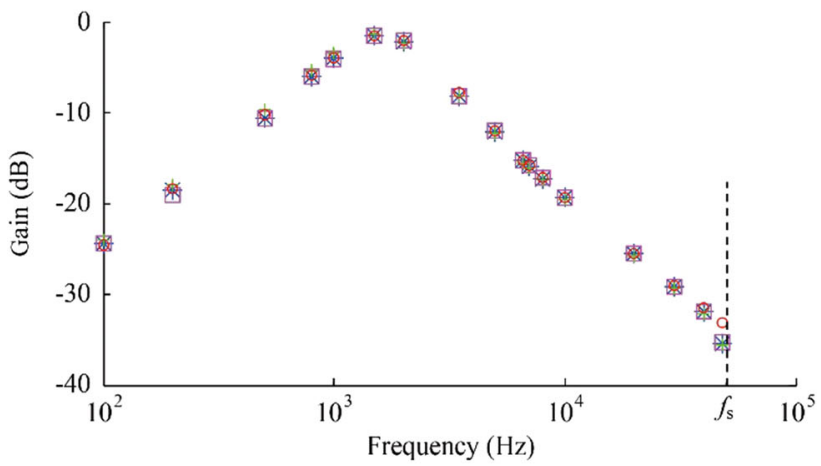

(d) Closed-loop output impedance $\left|Z_{\mathrm{o}}^{\mathrm{c}}(s)\right|$

* Ref.; $\square \mathrm{SWF}$; $+\mathrm{GAM} ; \circ \mathrm{SSA}$

Fig. 17 Closed-loop frequency response 


\subsection{Performance analysis}

Based on the results obtained in Sections 4.1 to 4.5 , the performance of the GAM is now compared with the implemented ideal, SWF and SSA models. The analysis mainly focuses on accuracy, frequency response as well as computational speed. The main outcomes regarding these three criteria are summarized in Table 3. It leads to the conclusion that the proposed GAM offers the best compromise in terms of accuracy, speed and wideband response for system-level analysis. Further details on the implementation of models are summarized in Table 4, while additional justifications are given below.

By first analyzing the time-domain simulation results, it is concluded that all the models accurately represent the averaged dynamic of the converter at the cross-over frequency $f_{\varphi \mathrm{m}}$ in Fig. 7. As expected, similar to the SWF model, the GAM method also considers the transient component at the switching frequency $f_{\mathrm{s}}$, but it is not the case with SSA in Fig. 6. The SWF model also considers the output voltage ripple at $6 f_{\mathrm{s}}$ (characteristic of the 3pDAB) while both GAM and SSA neglect this component in Fig. 8. Even if the transient responses of all the models are very similar for step function perturbations in Figs. 6 and 7 , it can also be seen from the frequency-domain analysis in Fig. 17 that, unlike the SWF model and the GAM, the SSA model is not accurate to reproduce the converter behavior for perturbations beyond $1 / 5$ of $f_{\mathrm{s}}$. These conclusions are summarized in Table 3.

Furthermore, from Figs. 9 and 11, it is concluded that both GAM and SSA provide a significant increase in computation speed when compared to the reference and SWF models. This is mainly explained by two fundamental differences. The primary reason is the fact that they both allow the use of larger simulation time steps $\Delta t$, which significantly increases the computation speed. It is also explained, to a lesser extent, by the reduction in the size of the network main system of equations in Table 4 , which, in this case, follows the modified-augmented-nodal analysis (MANA) formulation approach [27, 41].

However, for the same $\Delta t$, the benefit in computation speed in Fig. 9 of both the SSA and GAM methods compared to the reference model is much less significant than the reduction in the size of the network main system of equations in Table 4. This is because the size of the network main system of equations cannot be used alone to conclude on the relative simulation speed between models since control system equations are also solved separately from network equations in Table 4 [37, 41]. The computation burden of solving the larger non-linear and coupled set of control equations defined by (2)-(6) and (12)-(18) also explains why, for the same $\Delta t$, the computation time is higher with GAM as compared to SSA in Fig. 9.

Finally, it is also worth mentioning that the SWF, GAM and SSA models all lead to a reduced number of solution

Table 3 Comparison summary of 3p-DAB models

\begin{tabular}{llll}
\hline Model & Accuracy & Speed & Frequency response (up to) \\
\hline Ideal-model (Ref.) & 1 & 4 & $6 f_{\mathrm{s}}$ \\
Switching-function (SWF) & 1 & 3 & $6 f_{\mathrm{s}}$ \\
Generalized averaging (GAM) & 2 & 2 & $f_{\mathrm{s}}$ \\
State-space averaging (SSA) & 3 & 1 & $1 / 5^{\text {th }} f_{\mathrm{s}}$ \\
\hline
\end{tabular}

Note: Accuracy ranks from 1 (Most accurate) to 3 (Less accurate); speed ranks from 1 (Fastest) to 4 (Slowest)

Table 4 Summary of 3p-DAB model implementation in EMTP

\begin{tabular}{lcclll}
\hline Model & $\begin{array}{l}\text { Network } \\
\text { Nodes }\end{array}$ & $\begin{array}{l}\text { Size of the network main } \\
\text { system of equations }\end{array}$ & $\begin{array}{l}\text { Number of } \\
\text { non-zeros }\end{array}$ & $\begin{array}{l}\text { Number of solution points in } \\
\text { time-domain }\left(n_{\text {iter }}\right)\end{array}$ & $\begin{array}{l}\text { Control system equations state-space } \\
\text { formulation matrices size }\end{array}$ \\
\hline Ref. & $16^{*}$ & $43^{*}$ & $162^{*}$ & Eq. (20) & - \\
SWF & 18 & 29 & 99 & Eq. (19) & - \\
GAM & 6 & 8 & 24 & Eq. (19) & $\begin{array}{l}\boldsymbol{A}: 6 \times 6, \boldsymbol{B}: 6 \times 2, \\
\text { C: } 2 \times 6, \boldsymbol{D}=\mathbf{0}\end{array}$ \\
SSA & 6 & 8 & & & $\boldsymbol{A}=\mathbf{0}, \boldsymbol{B}=\mathbf{0}$, \\
& & & 24 & Eq. (19) & $\boldsymbol{C}=\mathbf{D}=2 \times 2$
\end{tabular}

Note: * means that each transistor is modeled with an ideal switch in parallel with an ideal free-wheeling diode 
points $\left(n_{\text {iter }}\right)$ in the time-domain as compared to the reference model in Table 4. In fact, for the simplest 3p-DAB model representation, the number of solution points for the SWF, GAM and SSA models is given by

$n_{\text {iter }}=t_{\text {sim }} / \Delta t$

while for the reference model, it is fundamentally higher by an additional term $12 t_{\mathrm{sim}} f_{\mathrm{s}}$,

$n_{\text {iter }}=t_{\text {sim }} / \Delta t+12 t_{\text {sim }} f_{\mathrm{s}}$

This difference is explained by the fact that, at each switching event, EMTP switches from a fixed time step trapezoidal integration method to backward Euler with two half-step $(\Delta t / 2)$ solutions [42]. This feature helps reduce numerical oscillations when ideal switches are used. It is not required to solve the SWF, GAM, and SSA models because the circuit topology is time-invariant. Furthermore, the simultaneous-switching control algorithm [43], which allows a simultaneous solution of network and control system equations at switching events, also explains why, for the same $\Delta t$, the computation time is higher with the reference model.

Finally, the results of the short-circuit test cases in Figs. 11, 15, 16 also show that the developed GAM can effectively be used for accelerating grid-level analyses. The GAM reduces the computation time by a factor of $1 / 30$ in the test case of Fig. 11, while still providing accurate results (error of less than $1 \%$ on the peak fault current). As seen in Figs. 15 and 16, the GAM also provides accurate results for typical power system transient analyses such as transient fault current and transient recovery voltage during arcing of circuit breakers. As previously mentioned in Section 4.4, it also provides a significant reduction in computation time for the large-scale test case (factor of $1 / 100)$.

\section{Conclusion}

In this paper, large-signal models of the $3 p-D A B$ converter are developed, analyzed, and implemented in EMTP. It is a key step toward reducing the computation time for time-domain system-level simulation of next-generation DC grids based on the 3p-DAB topology.

Three models are investigated in this paper: SWF, GAM and the SSA. Even if SSA significantly reduces the computation time, it has a limited precision for studying phenomena beyond $1 / 5$ of the converter switching frequency. Because they allow higher time steps, the SWF model and GAM both offer significant reduction in the computation time compared to the ideal-model, while still preserving the converter frequency characteristics up to its switching frequency. However, the maximum time step with the
SWF model is limited by the inclusion of the switchingeffect, which still leads to high computation time for system-level studies. Overall, the proposed GAM offers the best compromise in terms of accuracy, speed and wideband response.

Open Access This article is distributed under the terms of the Creative Commons Attribution 4.0 International License (http:// creativecommons.org/licenses/by/4.0/), which permits unrestricted use, distribution, and reproduction in any medium, provided you give appropriate credit to the original author(s) and the source, provide a link to the Creative Commons license, and indicate if changes were made.

\section{References}

1. Dragicevic T, Lu X, Vasquez JC et al (2016) DC microgrids Part II: a review of power architectures, applications, and standardization issues. IEEE Trans Power Electron 31(5):3528-3549

2. Boroyevich D, Cvetkovic I, Dong D et al (2010) Future electronic power distribution systems a contemplative view. In: Proceedings of the 12th international conference on optimization of electrical and electronic equipment, Brasov, Romania, 20-22 May 2010, pp 1369-1380

3. Rosero JA, Ortega JA, Aldabas E et al (2007) Moving towards a more electric aircraft. IEEE Aerosp Electron Syst Mag 22(3):3-9

4. Berger M, Lavertu C, Kocar I et al (2016) Proposal of a timedomain platform for short-circuit protection analysis in rapid transit train DC auxiliary systems. IEEE Trans Ind Appl 52(6):5295-5304

5. Sannino A, Postiglione G, Bollen MHJ (2003) Feasibility of a DC network for commercial facilities. IEEE Trans Ind Appl 39(5):1499-1507

6. Baran ME, Mahajan NR (2003) DC distribution for industrial systems: opportunities and challenges. IEEE Trans Ind Appl 39(6):1596-1601

7. Becker DJ, Sonnenberg BJ (2011), DC microgrids in buildings and data centers. In: Proceedings of the international telecommunications energy conference, Amsterdam, Netherlands, 9-13 October 2011, $7 \mathrm{pp}$

8. Berizzi A, Silvestri A, Zaninelli D et al (1996) Short-circuit current calculations for DC systems. IEEE Trans Ind Appl 32(5):990-997

9. Robinson J, Jovcic D, Joos G (2010) Analysis and design of an offshore wind farm using a MV DC grid. IEEE Trans Power Del 25(4):2164-2173

10. Thandi GS, Zhang R, Xing K et al (1999) Modeling, control and stability analysis of a PEBB based DC DPS. IEEE Trans Power Del 14(2):497-505

11. De Doncker RWAA, Divan DM, Kheraluwala MH (1991) A three-phase soft-switched high-power-density DC/DC converter for high-power applications. IEEE Trans Ind Appl 27(1):796-805

12. De Din E, Siddique HAB, Cupelli M et al (2018) Voltage control of parallel-connected dual-active bridge converters for shipboard applications. IEEE J Emerg Sel Topics Power Electron 6(2):664-673

13. Hou N, Song W, Zhu Y et al (2018) Dynamic and static performance optimization of dual active bridge DC-DC converters. J Mod Power Syst Clean Energy 6(3):607-618

14. Baars NH, Everts J, Wijnands CGE et al (2016) Performance evaluation of a three-phase dual active bridge DC-DC converter with different transformer winding configurations. IEEE Trans Power Electron 31(10):6814-6823 
15. Hamzeh M, Ghafouri M, Karimi H et al (2016) Power oscillations damping in DC microgrids. IEEE Trans Energy Convers 31(3):970-980

16. Mohan N, Robbins WP, Undeland TM et al (1994) Simulation of power electronic and motion control systems: an overview. Proc IEEE 82(8):1287-1302

17. Jin H (1997) Behavior-mode simulation of power electronic circuits. IEEE Trans Power Electron 12(3):443-452

18. Maksimovic D, Stankovic AM, Thottuvelil VJ et al (2001) Modeling and simulation of power electronic converters. Proc IEEE 89(6):898-912

19. Chiniforoosh S, Jatskevich J, Yazdani A et al (2010) Definitions and applications of dynamic average models for analysis of power systems. IEEE Trans Power Del 25(4):2655-2669

20. Ye Q, Mo R, Li H (2017) Low-frequency resonance suppression of a dual-active-bridge DC/DC converter enabled DC microgrid. IEEE J Emerg Sel Topics Power Electron 5(3):982-994

21. Zhao B, Song Q, Liu W et al (2014) Overview of dual-active bridge isolated bidirectional DC-DC converter for high-frequency-link power-conversion system. IEEE Trans Power Electron 29(8):4091-4106

22. Uhl R, Arasteh A, Monti A et al (2017) Nodal-reduced modeling of three-phase dual-active bridge converters for EMTP-type simulations. In: Proceedings of the 26th international symposium on industrial electronics, Edinburgh, Scotland, 19-21 June 2017, pp 787-792

23. Engel SP, Soltau N, Stagge H et al (2013) Dynamic and balanced control of three-phase high-power dual-active bridge DC-DC converters in DC-grid applications. IEEE Trans Power Electron 28(4):1880-1889

24. Salazar L, Joos G (1994) PSPICE simulation of three-phase inverters by means of switching functions. IEEE Trans Power Electron 9(1):35-42

25. Middlebrook RD, Cuk S (1976) A general unified approach to modelling switching-converter power stages. In: Proceedings of the power electronics specialists conference, Cleveland, USA, 8-10 June 1976, pp 18-34

26. Sanders S, Noworolski J, Liu X et al (1991) Generalized averaging method for power conversion circuits. IEEE Trans Power Electron 6(2):251-259

27. Mahseredjian J, Dennetiere S, Dube L et al (2007) On a new approach for the simulation of transients in power systems. Electr Power Syst Res 77(11):1514-1520

28. Berger M, Kocar I, Fortin-Blanchette H et al (2018) Hybrid average modeling of three-phase dual active bridge converters for stability analysis. IEEE Trans Power Del 33(4):2020-2029

29. Shi L, Lei W, Li Z et al (2018) Stability analysis of digitally controlled dual active bridge converter. J Mod Power Syst Clean Energy 6(2):375-383

30. Chandrasekar S, Gokaraju R (2015) Dynamic phasor modeling of type 3 DFIG wind generators (including SSCI phenomenon) for short-circuit calculations. IEEE Trans Power Del 30(2):887-897

31. Liu C, Bose A, Tian P (2014) Modeling and analysis of HVDC converter by three-phase dynamic phasor. IEEE Trans Power Del 29(1):3-12

32. Kish GJ, Lehn PW (2018) Linearized DC-MMC models for control design accounting for multifrequency power transfer mechanisms. IEEE Trans Power Del 33(1):271-281

33. Huang Y, Dong L, Ebrahimi S et al (2017) Dynamic phasor modeling of line-commutated rectifiers with harmonics using analytical and parametric approaches. IEEE Trans Energy Convers 32(2):534-547

34. Emadi A (2004) Modeling and analysis of multiconverter DC power electronic systems using the generalized state-space averaging method. IEEE Trans Ind Electron 51(3):661-668
35. Qin H, Kimball JW (2012) Generalized average modeling of dual active bridge DC-DC converter. IEEE Trans Power Electron 27(4):2078-2084

36. Li Z, Wang Y, Shi L (2017) Generalized averaging modeling and control strategy for three-phase dual-active-bridge DC-DC converters with three control variables. In: Proceedings of 32 nd annual IEEE applied power electronics conference and exposition, Tampa, USA, 26-30 March 2017, pp 1078-1084

37. Mahseredjian J, Dube L, Zou M et al (2006) Simultaneous solution of control system equations in EMTP. IEEE Trans Power Syst 21(1):117-124

38. Berger M, Grave JM, Lavertu C et al (2018) Modeling, simulation, and testing of switching surge transients in rapid transit vehicles dc power systems. IEEE Trans Ind Appl 54(1):822-831

39. Tremblay O, Dessaint LA (2009) Experimental validation of a battery dynamic model for EV applications. J World Electr Veh $3(1): 1-10$

40. Wu H, Yuan L, Sun L et al (2015) Modeling of current-limiting circuit breakers for the calculation of short-circuit current. IEEE Trans Power Del 30(2):652-656

41. Mahseredjian J, Dinavahi V, Martinez JA (2009) Simulation tools for electromagnetic transients in power systems: Overview and challenges. IEEE Trans Power Del 24(3):1657-1669

42. Marti J, Lin J (1989) Suppression of numerical oscillations in the EMTP. IEEE Trans Power Syst 4(2):739-747

43. Zou M, Mahseredjian J, Joos G et al (2006) Interpolation and reinitialization in time-domain simulation of power electronic circuits. Electr Power Syst Res 76(8):688-694

Maxime BERGER received the B.Eng. degree from the Universite du Québec à Rimouski, Rimouski, Canada, in 2014, and the M.A.Sc. degree from Polytechnique Montréal, Montréal, Canada, in 2016, where he is currently working toward the Ph.D. degree in electrical engineering. Since 2012, he is with Bombardier Transportation, St.Bruno, where he has been working in the Systems Integration Department. His research interests include power electronics, protection, and the simulation and analysis of power systems transients. His research is supported by Bombardier Transportation, the Fonds de Recherche du Québec-Nature et Technologies, and the Natural Sciences and Engineering Research Council of Canada through the Industrial Innovation Scholarship Program.

Ilhan KOCAR received the B.Sc. and M.Sc. degrees in electrical and electronics engineering from Orta Dogu Teknik Universitesi (ODTU/ METU), Ankara, Turkey, in 1998 and 2003, respectively, and the Ph.D. degree in electrical engineering from Polytechnique Montréal (affiliated with Université de Montréal), Canada in 2009. He worked as a Project Engineer at Aselsan Electronics Inc. (1998-2004) and as an R\&D Engineer at CYME International T\&D (2009-2011). He joined the faculty at Polytechnique Montreal in 2011. Ilhan's career highlights include contributions to professional tools and development of models and solver prototypes for power systems analysis from steady state to electromagnetic transients. He has performed many grid-consulting projects that cover design, modeling, analysis and validation of field measurements. His research is on the development of concepts, models and methods for power systems analysis and massive integration of renewables.

Handy FORTIN-BLANCHETTE received the B.Eng., M.Eng., and Ph.D. degrees in electrical engineering from the École de Technologie Supérieure (ÉTS), Montreal, Canada, in 2001, 2003, and 2010, respectively. From 1994 to 1997, he was engaged in industrial automation. From 1998 to 2000, he was with the Bombardier Transport-ETS Research Laboratory, Montreal, where he worked on a 
high power traction system. From 2001 to 2003, he was involved in the development of an electrical drive library for the Simulink (MATLAB) environment. From 2007 to 2010, he was with OPAL-RT Technologies, where he led CPU-based and FPGA-based power electronics real-time simulation projects. From 2010 to 2011, he was a Visiting Scholar at Center for Power Electronic and System, Virginia Polytechnic Institute and State University, Blacksburg, where he was involved in the packaging of high temperature converters for aircraft applications. He is presently an associate professor of Electrical Engineering at the École de Technologie Supérieure. His current research interests include EMI prediction, circuit modeling, and high density power converters packaging.
Carl LAVERTU received the B.Eng. degree in electrical engineering from the Université du Québec à Trois-Rivières, Trois-Rivières, Canada, in 1985. From 1985 to 1991, he was with Lauzon Lavertu Consultants, Inc., Drummondville, Canada. Since 1991, he is with Bombardier Transportation, St.-Bruno, where he is currently a Senior Expert in Power Electronics. He has been working on various rail projects being mainly involved in the design, fabrication, and testing of traction and auxiliary power converters, battery systems, door controllers, and lighting systems. He has two U.S. Patents. He is a Registered Professional Engineer in the province of Québec. 